\title{
OTIMIZAÇÃO DE PROCESSOS UTILIZANDO O FLUXOGRAMA COMO FERRAMENTA DE MAPEAMENTO DE PROCESSO: UM ESTUDO DE CASO EM UMA INDÚSTRIA DE EMBALAGENS FLEXÍVEIS
}

\author{
Ana Caroline Lins de Oliveira (UNIFAVIP) analinsproducao@gmail.com \\ Giseli Cezina Silva (UNIFAVIP) giselicezina@gmail.com
}

\section{Resumo}

Em busca de uma qualidade superior aos de seus concorrentes de mercado, o setor de transformação plástica de embalagens sente a necessidade de procurar por tecnologias em: maquinários, processos que possam agregar valor aos seus clientes, e formas de expansão de mercado. Visto que a impressão flexográfica tem uma maior liberdade quanto a impressão de seus substratos e formatos. Esse estudo faz uso de fluxogramas como ferramenta para mapear processos que, por meio da visualização de símbolos gráficos e tabelas, possibilitam ter uma visão clara de como todos os passos das tarefas em uma operação específica são realizados, auxiliando os gestores para uma tomada de decisão mais assertiva. Ao final desse trabalho será possível encontrar gargalos em meio ao setup interno de máquina após a cronometragem e sequenciamento de forma lógica de todas as etapas do processo para o entendimento de toda atividade realizada.

Palavras-chaves: Fluxograma. Mapeamento de processos. Impressão flexográfica.

\section{Introdução}

Segundo a ABIPLAST (2018), a indústria de transformação plástica é a quarta colocada em relação à geração de postos de trabalho entre as indústrias de transformação no Brasil, em 2018 o setor não teve um aumento relevante em suas atividades apresentando um crescimento de apenas $0,8 \%$, mas a perspectiva para o ano de 2019 foi de um crescimento de cerca de $2,5 \%$ em seu cenário econômico.

A flexografia tem evoluído muito ao longo dos anos pelo desenvolvimento da tecnologia em impressoras sofisticadas e pela qualidade de insumos e ferramentas que hoje são utilizadas. O processo de impressão flexográfico se torna muito versátil pela variedade de formatos e de 
substratos que podem ser impressos, hoje a flexografia é uma grande concorrente para as rotogravuras (SCARPETA, 2007).

"Flexografia é um sistema de impressão gráfica em que a fôrma (clichê de borracha ou fotopolímero) é relevográfica. São usadas tintas líquidas, à base de água ou solvente, curadas por luz UV (ultravioleta) ou EB (Electron Beam)”(ABTG, 2011, p. 6).

Segundo Scarpeta (2007), um dos processos principais da impressão está na entintagem da gravura a ser impressa, sendo composto por 3 elementos: o sistema de circulação de tinta por toda a impressora, o cilindro anilox que através das suas células dosadoras distribui a tinta de forma homogênea por toda superfície do clichê, e por último o sistema doctor blade que se encarrega de retirar todo excesso de tinta que fica disposto sobre a superfície do cilindro anilox.

O sistema encapsulado ou doctor blade é uma peça de extrema importância para a qualidade e controle de tinta na impressão, por ter uma câmara fechada que é composta por duas lâminas metálicas sendo capaz de diminuir a evaporação de solvente presente na tinta, conseguindo fazer a raspagem da tinta ao longo de toda superfície do cilindro anilox de forma igualitária (SCARPETA, 2007).

Este trabalho tem como objetivo fazer o mapeamento de processos através da ferramenta de fluxograma para descobrir gargalos no processo de setup interno de máquina no setor de impressão em uma indústria de embalagens flexíveis e trazer, por meio da análise do fluxograma de processos, uma solução prática para o problema identificado.

\section{Referencial teórico}

Serão abordados nesta seção os principais fundamentos para uma gestão de processos eficiente baseada no mapeamento de processos utilizando o fluxograma como ferramenta fundamental.

\subsection{Processos}

Segundo Scartenizi (2009), processos são atividades lógicas sequenciadas com início e fim bem determinado, e essas atividades passam por um processo de transformação na qual agregam valor ao produto/serviço. Essa transformação é gerada a partir da etapa de entrada de insumos (matéria prima) e entrega do produto final. 
"Os processos podem variar bastante entre si. Alguns são extremamente elementares, outros, extremamente complexos. Um processo também pode ser dividido, ou quebrado, em outros processos menores que podem ser considerados subprocessos" (PEINADO; GRAEML, 2007, p.142).

Figura 1 - Processo de transformação
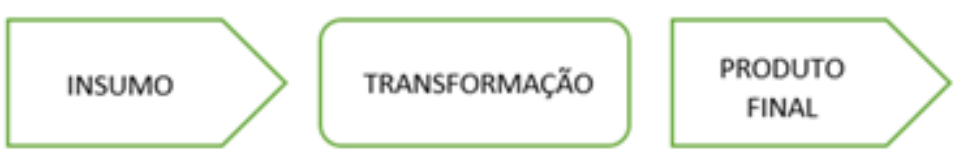

Fonte: Adaptado de Scartezini (2020)

O estudo para a análise de métodos ou processos de trabalho aborda técnicas que detalham cada operação de uma dada tarefa com o objetivo de eliminar qualquer elemento desnecessário à operação e também conseguir determinar o melhor e mais eficiente método para executar cada operação da tarefa, otimizando o processo (PEINADO; GRAEML, 2007).

\subsection{Gestão de processos}

Segundo a ABPMP (2013), o gerenciamento de processos não agrega valor diretamente para o cliente, mas é através do seu propósito de medir, monitorar e controlar os processos durante a realização de atividades que a gerência consegue atingir o objetivo e as metas que são traçadas para a empresa, conseguindo assim administrar o presente e, o futuro do negócio.

O gerenciamento de processos nas organizações tem como intuito principal aumentar os seus níveis de desempenho e consequentemente os seus resultados através de uma visão sistemática da organização a partir do controle, documentação, medições e de monitoramento de seus processos. Com uma gestão eficiente de processos as organizações conseguem ser mais precisas em suas entregas de produto/serviço, conseguem também otimizar tempo e recursos na produção e padronizar produtos/serviços que geram uma maior qualidade e se transforma em satisfação por parte de seus clientes.

\subsection{Mapeamento de processos}

Segundo Scartezini (2009), o mapeamento de processos é uma ferramenta analítica que pode ser usada pela gerência para analisar processos existentes ou para criação de novos processos. Toda a sequência de atividades realizadas em um processo deve ser descrita no mapeamento de 
processos, na qual deve ser representado de forma gráfica com o uso da ferramenta fluxograma. Processos industriais muitas vezes são complexos e com muitos passos, e devido ao imenso número de processos de execução de tarefas, é impraticável querer avaliar e melhorar todos os processos ao mesmo tempo, pois é necessário ainda um profundo conhecimento do processo e de suas tarefas, bem como o que o levou a ser executado de tal forma no passado, conhecendo ainda quais as premissas adotadas na definição de um processo, bem como o que pode ser alterado, ou deixado de existir. A alteração do processo de forma pouco cuidadosa, e sem atenção, pode levar a um novo processo deficiente (PEINADO; GRAEML, 2007).

\subsubsection{Etapas do mapeamento de processos}

Para analisar quais os processos possuem mais potencial em sua alteração, deve-se levar em consideração aqueles com mais gargalos, que frequentemente param por alguma razão, com muitas operações ou intensivos em mão-de-obra, com excesso de retrabalho, com problemas da qualidade e dispendiosos (PEINADO; GRAEML, 2007).

A abordagem para estudo dos métodos de trabalho envolve sequencialmente seis passos, são eles: selecionar o trabalho a ser estudado, registrar todos os fatos relevantes do método presente, examinar esses fatos crítico e sequencialmente, desenvolver o método mais prático, econômico e efetivo, implantar o novo método, e manter o método pela checagem periódica dele em uso (SLACK; CHAMBERS; JOHNSTON, 2002).

A análise e estudo do processo podem ser usados para uma operação já existente ou para uma operação nova. Através desse estudo é possível melhorar as atividades já realizadas, ou propor novas maneiras de fazer determinada atividade de forma que seja mais eficiente (PEINADO; GRAEML, 2007). A análise de um processo de trabalho deve seguir uma sequência lógica de ações que, conforme Slack, Chambers e Johnston (2002) é descrita como:

Passo 1 - Selecionar o trabalho a ser estudado: selecionar quais operações serão estudadas, devendo ser escolhidas aquelas com maior retorno sobre o investimento do tempo de estudálas, as que oferecem o maior escopo para melhorias, ou que estão causando gargalos, atrasos, ou problemas na operação;

Passo 2 - Registrar o método atual: a ferramenta mais comumente utilizada para tal finalidade é o fluxograma, e o objetivo é trazer maior entendimento do próprio trabalho através da análise crítica, o que pode levar a novas formas de fazê-lo; 
Passo 3 - Examinar os fatos: possivelmente o passo mais importante, cuja ideia é examinar o método atual inteiro e criticamente, este passo é geralmente feito usando a técnica do questionamento;

Passo 4 - Desenvolver um novo método: o objetivo nessa etapa é eliminar partes inteiras da atividade; combinar elementos; mudar a sequência de eventos, de modo que melhore a eficiência do trabalho; ou simplificar a atividade para reduzir o conteúdo de trabalho;

Passos 5 e 6 - Instalar o novo método e mantê-lo regularmente: o objetivo aqui é instalar os novos processos, de modo a garantir a continuidade das melhorias implementadas.

\subsection{Fluxograma de processos}

Os fluxogramas são formas de representar, por meio de símbolos gráficos, a sequência dos passos de um trabalho para facilitar sua análise e interpretação. Um fluxograma é um recurso visual utilizado pelos gerentes de produção para analisar sistemas produtivos, buscando identificar oportunidades de melhorar a eficiência dos processos. Os fluxogramas possuem a vantagem de uma visualização mais esclarecedora e rápida, permitindo um maior entendimento de tabelas, e do processo como um todo (PEINADO; GRAEML, 2007).

A ferramenta fluxograma de processos através de gráficos permite a visualização de todas as etapas de dentro de um processo para que a gerência possa ter uma visão global e que, isso possa auxiliar em sua tomada de decisão. O desenho do fluxograma é feito a partir de símbolos que são elementos de um processo (DAVIS; AQUILANO; CHASE, 2001). O fluxograma pode ser representado por símbolos conforme mostrado no Fluxograma 1: 
Fluxograma 1 - Exemplo de fluxograma

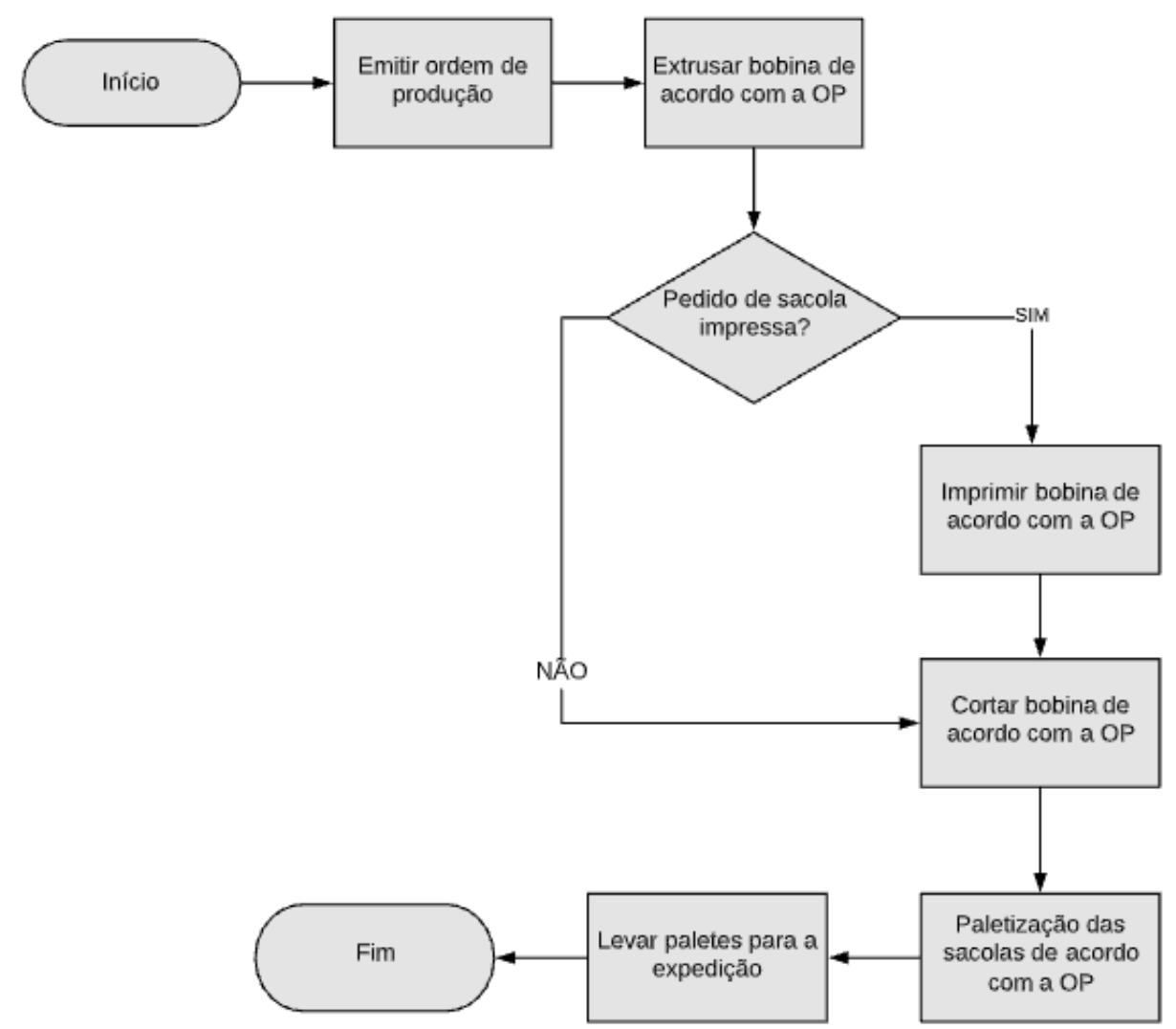

Fonte: As autoras (2020)

O fluxograma do processo é uma representação gráfica visual, de rápida visualização que busca sequenciar de forma bem definida o que ocorre com o material ou conjunto de materiais, durante uma sequência de fases do processo produtivo (MOREIRA, 2012). A representação gráfica desses símbolos pode ser visualizada através do Quadro 1:

Quadro 1 - Símbolos do fluxograma de processos

\begin{tabular}{|c|c|l|}
\hline Atividade & Símbolo & \multicolumn{1}{|c|}{ Exemplos } \\
\hline Operação & & Pregar um prego, misturar insumos e digitar. \\
\hline Transporte & & $\begin{array}{l}\text { Mover material com carrinho, mover material com } \\
\text { correia e carregamento de material. }\end{array}$ \\
\hline Estocagem & $\checkmark$ & $\begin{array}{l}\text { Líquidos em contêiners, produtos acabados em } \\
\text { paletes e documentos em arquivo. }\end{array}$ \\
\hline Demora & & $\begin{array}{l}\text { Esperando elevador, aguardando processamento de } \\
\text { material e formulários a serem preenchidos. }\end{array}$ \\
\hline Inspeção & & $\begin{array}{l}\text { Examinando peças acabadas, verificando a pressão } \\
\text { em uma caldeira e vereificando instruções escritas. }\end{array}$ \\
\hline
\end{tabular}


É comum a utilização de formulários impressos para a elaboração de fluxogramas. O Quadro 2 apresenta um modelo comumente utilizado em processos industriais.

Quadro 2 - Modelo de fluxograma de processo

\begin{tabular}{|c|c|c|c|c|}
\hline \multicolumn{5}{|c|}{ DIAGRAMA DE FLUXO DE PROCESSO } \\
\hline \multicolumn{2}{|c|}{ Processo: } & \multicolumn{3}{|l|}{ Local: } \\
\hline \multicolumn{2}{|c|}{ Produto: } & \multicolumn{3}{|l|}{ Analista } \\
\hline № & Descriçâo da atividade & Duraçào & $\begin{array}{l}\text { Tipo de } \\
\text { atividade }\end{array}$ & $\begin{array}{l}\text { Distancia } \\
\text { percorrida }\end{array}$ \\
\hline 1 & & & $0 \Leftrightarrow D \perp v$ & \\
\hline 2 & & & $0 \Rightarrow D \perp v$ & \\
\hline 3 & & & $0 \Rightarrow D \pm v$ & \\
\hline 4 & & & $0 \Rightarrow D \simeq v$ & \\
\hline 5 & & & $0 \Leftrightarrow D \square v$ & \\
\hline 6 & & & $0 \Rightarrow D \square v$ & \\
\hline 7 & & & $0 \Rightarrow D \pm v$ & \\
\hline 8 & & & $0 \Rightarrow D \square v$ & \\
\hline 9 & & & $0 \Leftrightarrow D \square v$ & \\
\hline 10 & & & $0 \Leftrightarrow D \simeq v$ & \\
\hline 11 & & & $0 \Leftrightarrow D \pm v$ & \\
\hline 12 & & & $0 \Rightarrow D=v$ & \\
\hline 13 & & & $0 \Leftrightarrow D E v$ & \\
\hline 14 & & & $0 \Leftrightarrow D=v$ & \\
\hline 15 & & & $0 \Leftrightarrow D E v$ & \\
\hline 16 & & & $0 \Leftrightarrow D=v$ & \\
\hline 17 & & & $0 \Leftrightarrow D=v$ & \\
\hline 18 & & & $0 \Leftrightarrow D \square v$ & \\
\hline 19 & & & $0 \Leftrightarrow D \pm v$ & \\
\hline 20 & & & $0 \Leftrightarrow D \simeq v$ & \\
\hline
\end{tabular}

Fonte: Peinado e Graeml (2007)

\subsection{Doctor Blade}

Antigamente usava-se lâminas adaptadas de rotogravura. Atualmente, já existem lâminas apropriadas para utilização na flexografia. As lâminas podem ser de aço, plástico e de aço revestidas com cerâmica (SCARPETA, 2007). A Figura 2 a seguir mostra o doctor blade e seus componentes:

Figura 2: Sistema doctor blade

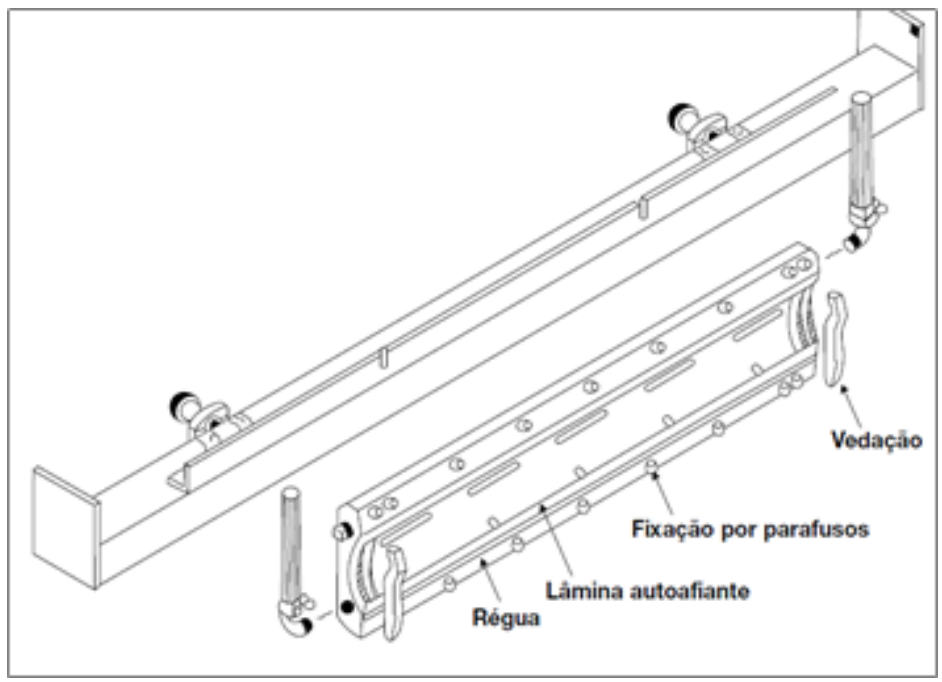

Fonte: Scarpeta (2007). 
O sistema encapsulado, também chamado de doctor blade (lâmina dosadora), permitiu um controle maior da tinta, pois fica menos exposta ao ar, o que diminui a evaporação do solvente, permitindo uma raspagem igualitária em toda a superfície do anilox. O sistema encapsulado tem a vantagem de ser uma câmera fechada em que a tinta circula e depois volta para reservatório. Isto permite uma economia entre $20 \%$ a $35 \%$ no consumo de solvente (SCARPETA, 2007).

Entretanto, bons resultados são obtidos com a utilização de lâminas de aços, pois elas mantêm por mais tempo o fio de raspagem, se em comparação aos convencionais que logo precisarão de afiação e mudarão o ângulo de contato. $O$ ângulo de contato deve estar entre $30^{\circ}$ e $35^{\circ}$. Além disso, deve-se usar um contra faca para melhorar a eficiência da raspagem (SCARPETA, 2007). Deve-se prestar atenção em sua montagem, pois a montagem incorreta poderá ocasionar uma raspagem irregular no anilox, contribuindo para um desgaste de forma irregular do mesmo (SCARPETA, 2007).

\section{Metodologia}

O presente trabalho tem natureza de pesquisa aplicada e qualitativa quanto a análise de dados e informações. O objetivo da pesquisa é de caráter exploratório que, segundo Prodanov e Freitas (2013), visa esclarecer as ideias e o desenvolvimento do trabalho através de uma visão completa de todos os fenômenos que acontecem e são poucos explorados, a partir de estudos aprofundados é possível aprimorar o conhecimento e servir de base para futuras pesquisas.

Quanto aos seus procedimentos, é classificado como estudo de caso pela necessidade de um estudo minucioso e profundo para a coleta e análise de dados relacionados a uma determinada área de pesquisa (PRODANOV; FREITAS, 2013).

O estudo de caso iniciou-se no setor de impressão, pois este é o setor com maior número de problemas, dentre os vários processos de impressão escolheu-se aquele com maior gargalo, ou seja, inicialmente priorizou-se a troca e limpeza do doctor blade. O estudo foi realizado em duas etapas: a primeira fase foi constituída basicamente de observação, onde foi utilizado como ferramentas um cronômetro, papel e caneta para captação dos dados, além de posterior conversa com operadores e encarregado para compreensão do processo. Na segunda fase começou a ser realizada a análise e discussão, na qual foi realizado um estudo aprofundado do manual técnico da máquina para compreensão do que poderia ou não ser feito, verificando quesitos de 
segurança e qualidade no processo de impressão. Ainda na fase de análise foi utilizado o Microsoft Excel para organização dos dados e confecção de um fluxograma vertical, e posteriormente para uma melhor visualização e entendimento dos dados foi feito um fluxograma do processo com o auxílio do Microsoft Visio. O estudo teve duração total de aproximadamente 2 meses.

\section{Estudo de caso}

A empresa estudada começou às suas atividades no ano de 2009 , com intuito de atender à crescente demanda no Nordeste brasileiro por embalagens flexíveis para o segmento comercial e de serviços, localizada estrategicamente no Agreste pernambucano. Os seus produtos atendem ao segmento tanto de varejistas como de atacadistas e de serviços, dentro do padrão de medida e espessura do mercado ou de acordo com a necessidade de seus clientes. Hoje a empresa atende à demanda de 15 estados do país, com atuação fortemente em Pernambuco, chegando a atender 129 cidades do estado.

Inicialmente, para a análise de processos, escolheu-se o setor de impressão, pois este é o setor com maior tempo de setup, menor produtividade, e maior número de reclamações por parte da gerência, constituindo assim um forte candidato ao estudo e mapeamento de processos. Para maior compreensão foi analisado o setup, todos os tempos para a realização de todas as atividades referentes ao processo de impressão, as atribuições de cada operador, e o manual de instruções da máquina, a fim de compreender melhor o processo e adquirir uma visão global.

O setor de impressão constitui-se de um impressor responsável pela tomada de decisão, e a execução de processos críticos que exigem maior conhecimento e familiaridade, sendo ele o responsável pelas falhas de impressão, e erros operacionais que possam haver no maquinário e turno que se encontra, cada impressor se responsabiliza e opera uma impressora. E cada impressor possui um auxiliar de impressão, que ficará sob sua liderança e terá como objetivo ajudá-lo, dando suporte e ficando responsável por atividades mais simples como a busca e troca de bobinas, medição de viscosidade, limpeza, troca da lâmina do doctor blade e etc.

Durante a análise de processos dividiu-se o setup em duas partes para a facilitação da compreensão, sendo o setup interno constituído por atividades do pedido atual e realizadas com a máquina parada, e o setup externo onde os operários aprontam as ferramentas necessárias para o próximo pedido com a máquina em movimento. 
Foi possível identificar diversos gargalos no processo de impressão, entretanto priorizou-se aqueles com maior duração no setup interno, maior recorrência e que impactavam diretamente no resultado final da impressão. Sob esses parâmetros, escolheu-se a análise aprofundada e detalhada do processo de troca de lâminas e limpeza do doctor blade.

No Fluxograma 2 é descrito como o processo de troca de lâminas do doctor blade é realizado, tem-se em azul as atividades realizadas pelo impressor e em verde as atividades do auxiliar:

Fluxograma 2 - Processo atual

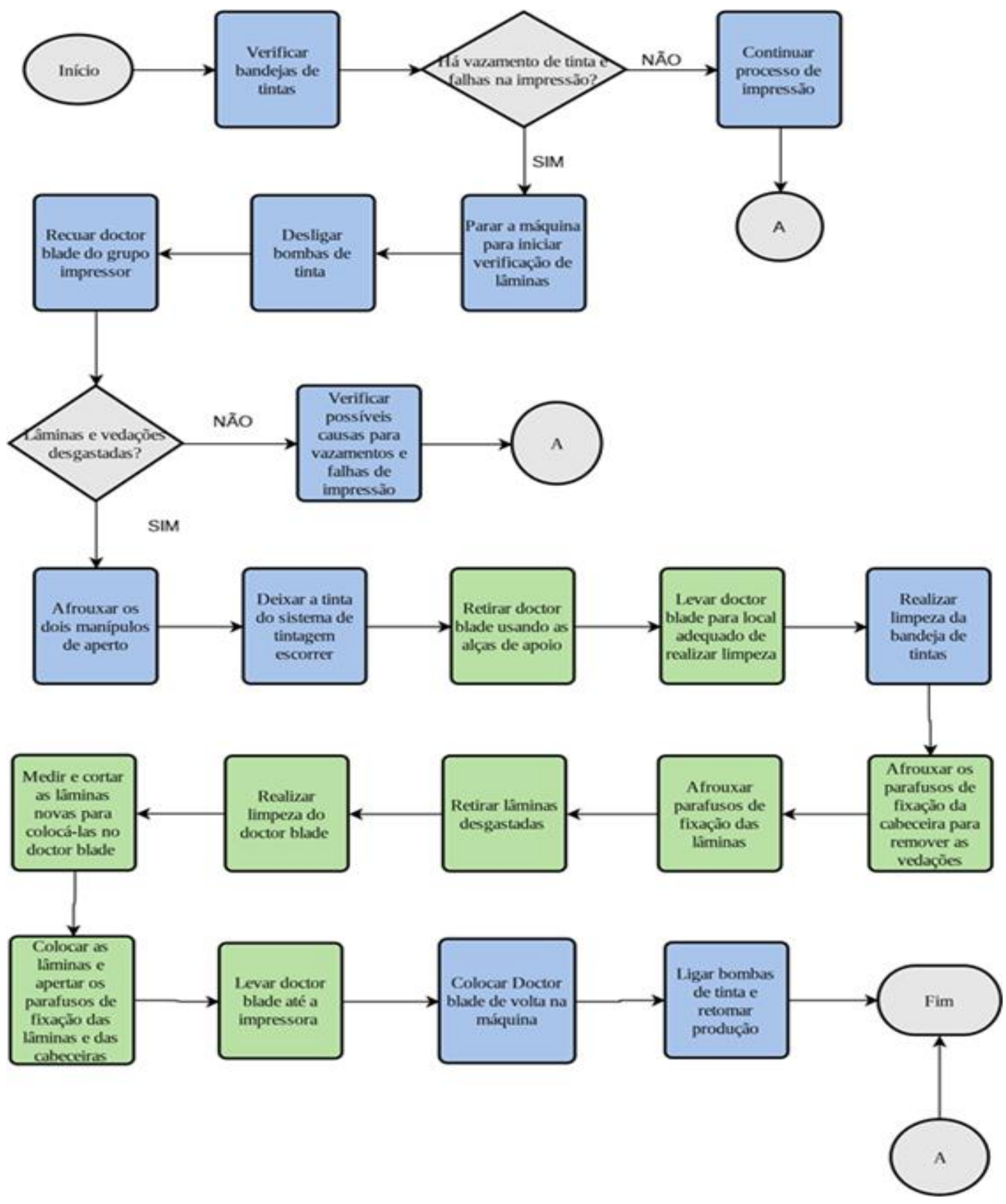

Fonte: As autoras (2020) 
Após o acompanhamento de várias trocas de lâminas e limpezas do doctor blade, foi possível desenhar o processo em questão, através de um fluxograma, que pôde trazer uma maior compreensão e visualização do processo como um todo. Verificou-se inicialmente no fluxograma a sequência de passos, identificando que todo o processo era realizado em apenas um setup interno com a máquina parada.

Entretanto, para uma análise mais eficaz foram necessárias a cronometragem e a utilização do fluxograma vertical, onde foi detalhado a sequência de passos no processo, o tempo para a realização das atividades e o responsável. O fluxograma vertical está representado no Quadro 3 a seguir:

Quadro 3 - Processo atual detalhado

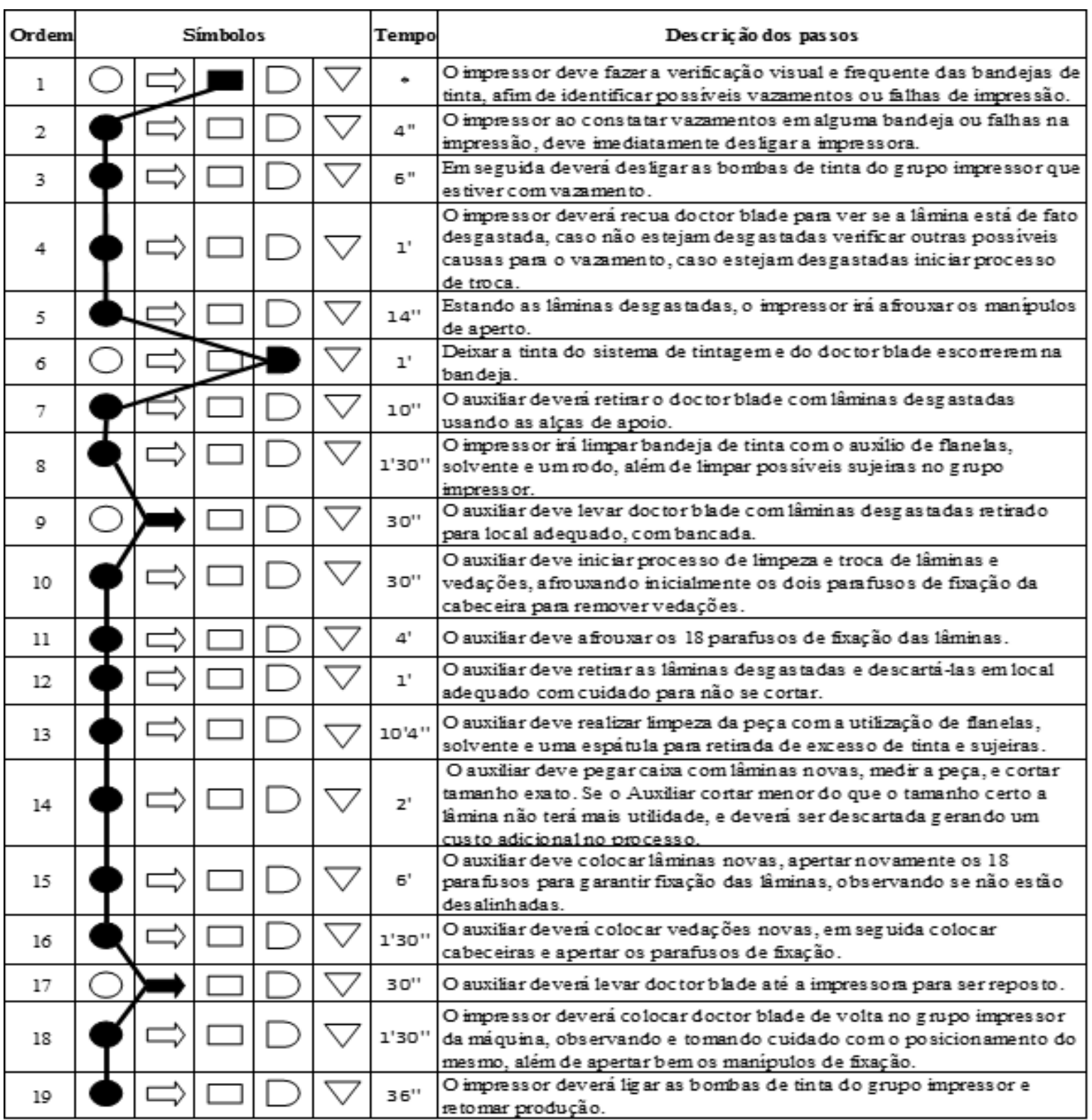


Como mostrado no Quadro 3, toda atividade de troca de lâminas do doctor blade leva em média 32 minutos e 13 segundos para ser realizada, sendo possível destacar duas atividades com maior duração. A primeira leva em torno de 10 minutos e é a limpeza de toda a peça do doctor blade, onde o auxiliar deverá retirar todo o excesso de tinta da superfície deixando a peça totalmente limpa. A segunda é a troca da lâmina desgastada por uma nova, levando em média 6 minutos, onde o auxiliar deverá colocá-la com cuidado observando seu alinhamento e em seguida apertar os parafusos de fixação da lâmina.

Encontrado os gargalos responsáveis por quase metade do tempo em que a máquina tinha que ficar parada no processo, foi estudado meios de solucionar o problema. A solução proposta foi a utilização de doctor blade reserva na troca de lâminas desgastadas, que facilitará e reduzirá o tempo de máquina parada em um setup interno, visto que, ao invés de acontecer todo o processo de troca das lâminas desgastadas e de limpeza enquanto a máquina estivesse parada, agora a troca seria imediata de um doctor blade por outro já pronto, com lâminas e vedações novas. O setup agora foi dividido em 2, setup interno e externo. O Fluxograma 3 mostra como o setup interno de troca e limpeza ocorreria com o uso do doctor blade reserva.

Fluxograma 3 - Processo de setup interno proposto

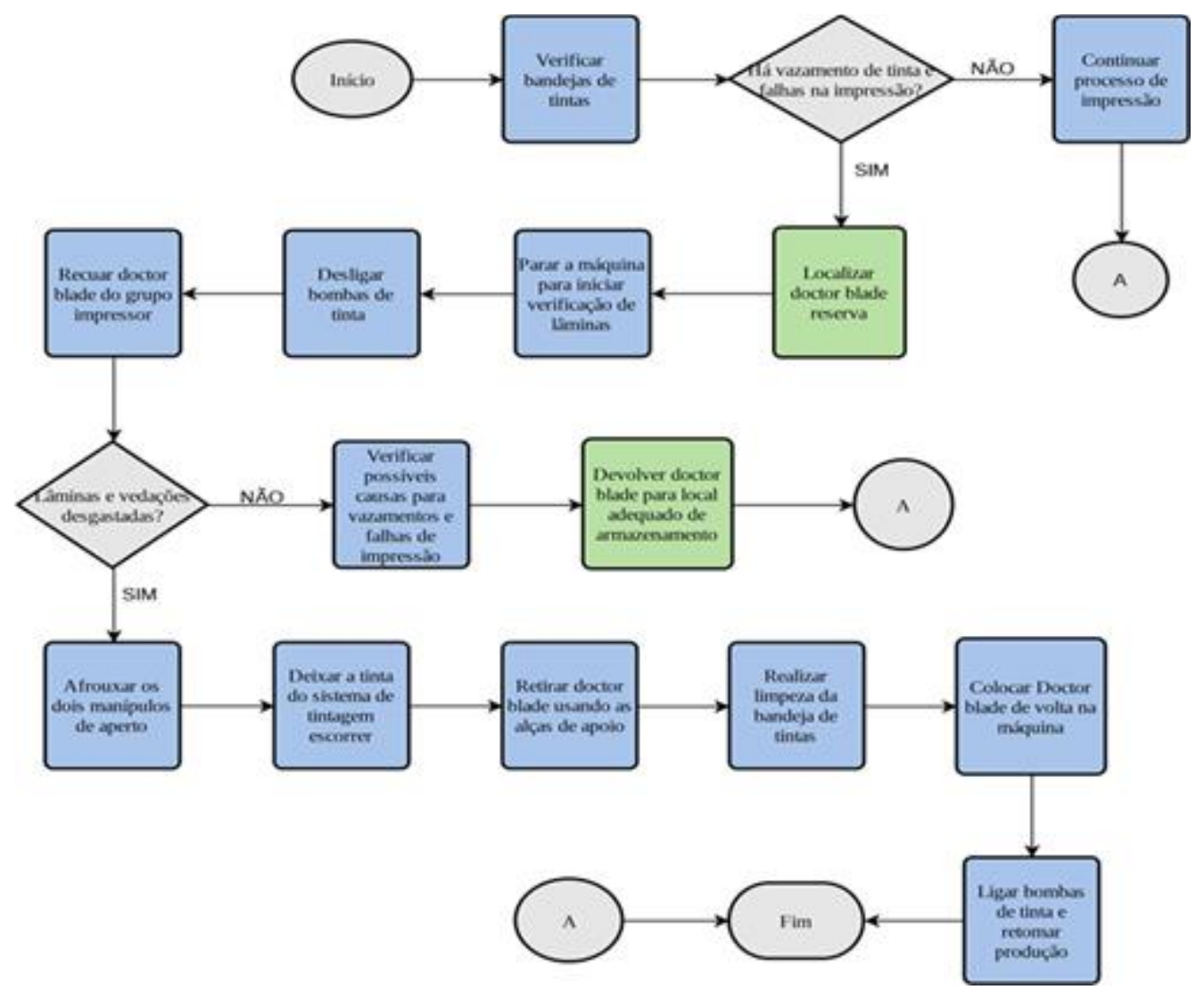

Fonte: As autoras (2020) 
Para analisar se a solução proposta diminuiria de fato o tempo de máquina parada e o tempo de setup, foi realizado novamente o acompanhamento do processo e a cronometragem de todas os passos conforme o sequenciamento do Fluxograma 3. No Quadro 4 é possível visualizar o tempo de cada passo e a descrição de como cada passo deverá ser realizado.

Quadro 4 - Processo proposto

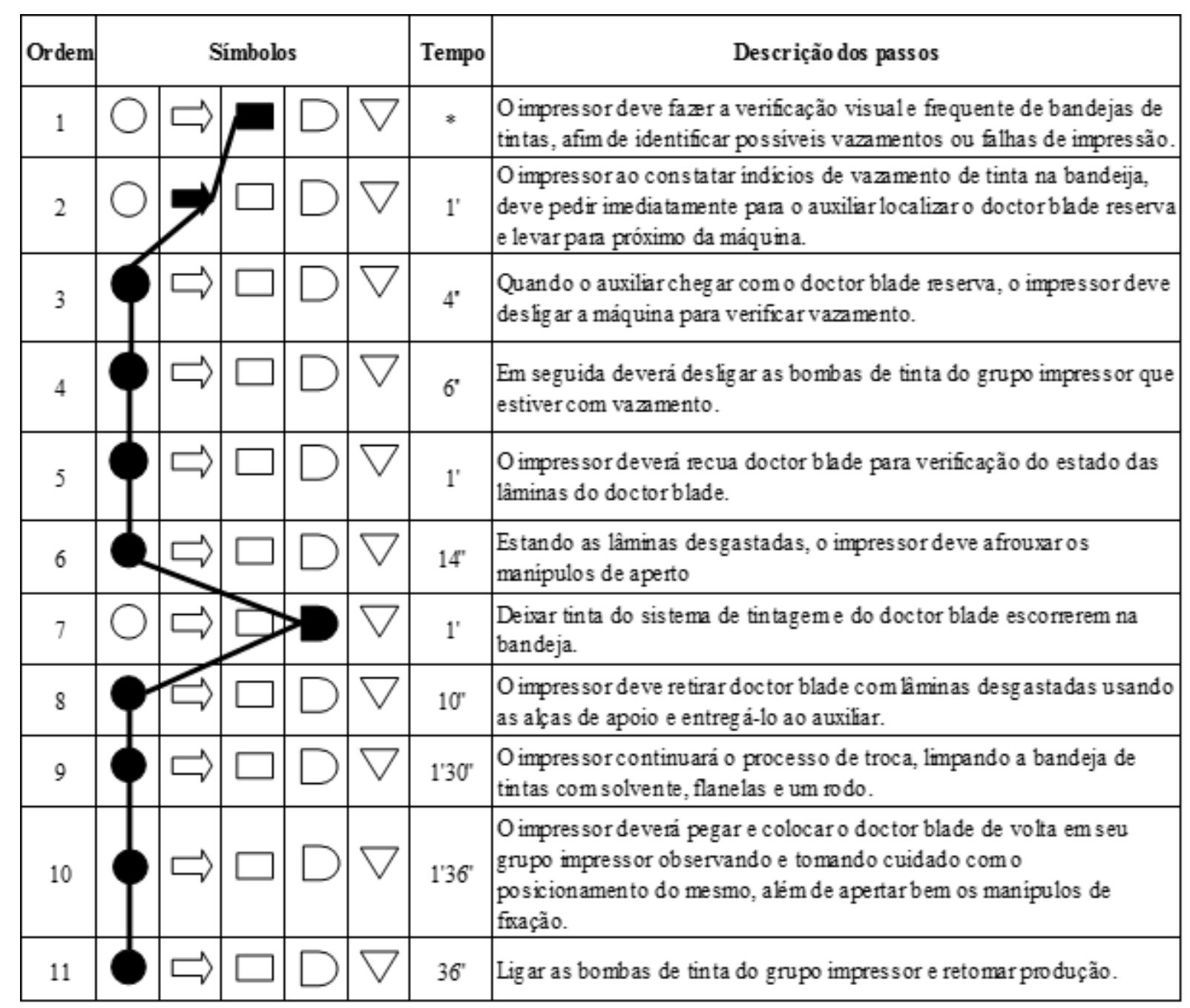

Fonte: As autoras (2020)

Ao colocar os dados em um novo fluxograma foi possível verificar que de fato um doctor blade reserva diminuiria significativamente o tempo em relação a como o processo atualmente é realizado no setup interno. O que pode ser facilmente verificado na Tabela 1 abaixo: 
Tabela 1 - Comparação de processos do setup interno

\begin{tabular}{ccccc}
\hline Atividade & $\begin{array}{c}\text { Processo } \\
\text { presente }\end{array}$ & $\begin{array}{c}\text { Tempo } \\
\text { presente (min) }\end{array}$ & $\begin{array}{c}\text { Processo } \\
\text { proposto }\end{array}$ & $\begin{array}{c}\text { Tempo } \\
\text { proposto (min) }\end{array}$ \\
\hline Operação & 15 & $30^{\prime} 13^{\prime \prime}$ & 8 & $5^{\prime} 15^{\prime \prime}$ \\
Transporte & 2 & $1^{\prime}$ & 1 & $1^{\prime}$ \\
Espera & 1 & $1^{\prime}$ & 1 & $1^{\prime}$ \\
Inspeção & 1 & 0 & 1 & 0 \\
Armazenagem & 0 & 0 & 0 & 0 \\
\hline Total & 19 & $\mathbf{3 2}^{\prime} 13^{\prime \prime}$ & 11 & $\mathbf{7}^{\prime} 15^{\prime \prime}$ \\
\hline
\end{tabular}

Fonte: As autoras (2020)

Com o uso do doctor blade reserva na tabela 1 é possível perceber a redução de 15 para 8 processos realizados com a máquina parada, e consequentemente uma redução no tempo de realização das atividades que antes eram de 32 minutos e 13 segundos passando a serem realizadas em apenas 7 minutos e 15 segundos, o que representa uma diminuição de quase $78 \%$ no tempo de execução da troca do doctor blade.

Quadro 5 - Processo proposto setup externo

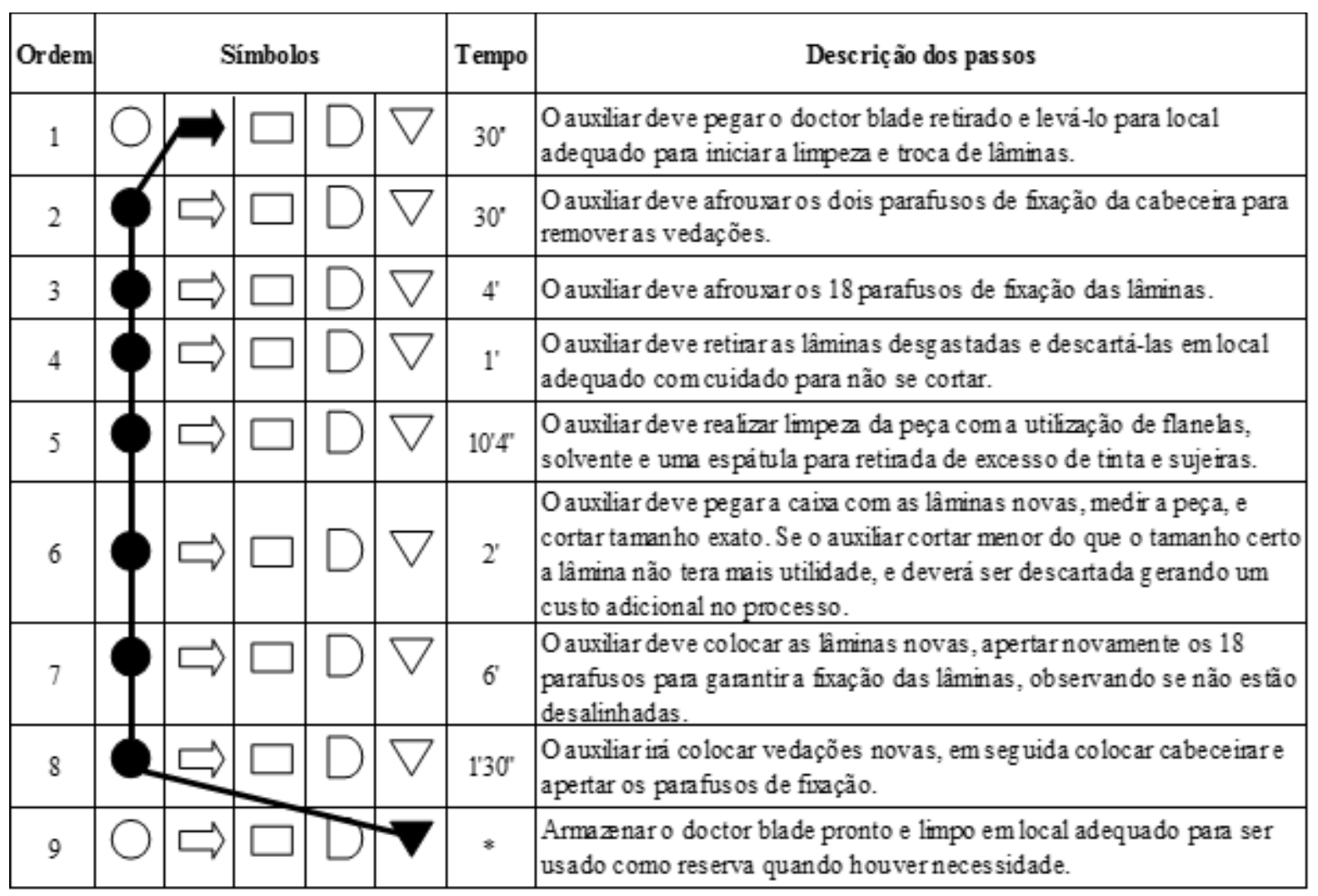


O processo de troca de lâminas agora será realizado como mostra o passo a passo no Quadro 5, sendo feito em um setup externo, sem ser preciso a máquina está parada para realização do processo. A troca de lâminas agora levará em média 25 minutos e 34 segundos, e deve ser realizada sempre que houver uma troca de doctor blade, em seguida o doctor blade com novas lâminas deve ser armazenado em um local apropriado, pronto para próxima troca.

\section{Conclusão}

O fluxograma e o mapeamento de processos são ferramentas importantes para a compreensão, análise e otimização de processos, pois através delas é possível identificar com maior clareza quais as atividades apresentam maiores gargalos e, portanto, podem ser melhoradas.

Com a aplicação dessas ferramentas, analisou-se cada atividade verificando quais poderiam ser feitas em um setup interno, e quais poderiam ser feitas em um setup externo. Diante desta análise, chegou-se a uma solução que consistia na utilização de um doctor blade reserva, na criação e divisão de setups. A proposta de solução tem como meta uma redução de setup interno de 32 minutos e 13 segundos para 7 minutos e 15 segundos, o que representa uma diminuição de aproximadamente $77,75 \%$ no setup com máquina parada.

A solução proposta ainda tem a vantagem ser de baixo custo, pois foi verificado que haviam dentro da própria empresa 3 doctor blades reservas para a impressora em questão, e que a manutenção e compra dos itens que faltavam não constituíam um alto valor. Os doctor blades reservas encontravam-se estocados e não eram usados porque estavam sujos, sem alguns parafusos, e um deles possuía a alça de apoio quebrada. Os próximos passos consistem na elaboração de um Procedimento Operacional Padrão (POP), de treinamento e acompanhamento do processo para garantir as metas esperadas.

\section{Referências}

ASSOCIAÇÃO BRASILEIRA DE INDÚSTRIA DO PLÁSTICO - ABIPLAST. Relatório de atividades 2018. Disponível em: <http://www.abiplast.org.br/publicacoes/relatorio-2018/>; Acesso em 10 de maio de 2020.

ASSOCIAÇÃO BRASILEIRA DE TECNOLOGIA GRÁFICA. ABTG. Manual de impressão flexográfica. 2011.

ASSOCIATION OF BUSINESS PROCESS MANAGEMENT PROFESSIONALS - ABPMP. Guia para o Gerenciamento de Processos de Negócio: Corpo Comum de Conhecimento. [S.1], 2009.

DAVIS, Mark M.; AQUILANO, Nicholas J.; CHASE, Richard B. Fundamentos da Administração da Produção. 3. ed. Porto Alegre: Bookman Editora, 2001. 
Gestão de processos: o que é, quais os benefícios e como implantar na sua organização. Disponível em: \&lt;https://www.euax.com.br/2019/04/gestao-de-processos/\&gt; Acesso 10 de maio de 2020.

MOREIRA, Daniel Augusto. Administração da produção e operações. 2.ed. rev. e ampl. São Paulo: Cengage Learning, 2012.

O que preciso saber sobre gestão de processos organizacionais?. Disponível em: \&lt;https://www.sispro.com.br/blog/erp/o-que-preciso-saber-sobre-gestao-de-processos-organizacionais/ \&gt; Acesso em 02 de maio de 2020.

PEINADO, Jurandir; GRAEML, Alexandre Reis. Administração da produção: operações industriais e de serviços. Curitiba: UnicenP, 2007.

PRODANOV, C. C.; FREITAS. E. C. Metodologia do trabalho científico: Métodos e técnicas da pesquisa e do trabalho acadêmico. $2^{\circ}$ edição. Novo Hamburgo, Rio Grande do Sul. Feevale, 2013

SCARTEZINI, Luís Maurício Bessa. Análise e Melhoria de Processos. Apostila. Goiânia, 2009.

SLACK, Nigel; STUART, Chambers; JOHNSTON, Robert. Administração da produção. 2. ed. São Paulo: Atlas, 2002.

SCARPETA, Eudes. Flexografia manual prático. 1.ed. São Paulo: Bloco Comunicação Ltda, 2007. 